KUSIK L.I.

\title{
EXISTENCE CONDITIONS AND ASYMPTOTICS FOR SOLUTIONS OF ONE CLASS OF SECOND-ORDER DIFFERENTIAL EQUATIONS
}

For a differential equation of the second order of the form $y^{\prime \prime}=\alpha_{0} p(t) \varphi_{0}(y)\left|y^{\prime}\right|^{\sigma_{1}}$, where $\alpha_{0} \in\{-1,1\}, p:\left[a, \omega[\longrightarrow] 0,+\infty\left[\right.\right.$ is continuous function, $\left.\varphi_{0}: \Delta_{Y_{i}} \longrightarrow\right] 0,+\infty[$ is continuous regularly varying as $y \rightarrow Y_{0}$ the function of $\sigma_{0}$ order, and $\sigma_{0}+\sigma_{1}=1, \Delta_{Y_{i}}(i \in\{0,1\})$ is a oneside neighborhood of $Y_{i}$ and $Y_{i} \in\{0 ; \pm \infty\}(i \in\{0,1\})$, the question of the existence of solutions for which $\lim _{t \uparrow \omega} y^{(i)}(t)=Y_{i}(i \in\{0,1\})$ is considered. Involvement in the 1980s in V.Marič, M. Tomič's works in the study of two-term second-order differential equations $y^{\prime \prime}=p(t) \varphi(y)$ with regularly varying nonlinearities in zero made it possible to find two-sides estimates of solutions tending to zero as $t \rightarrow+\infty$. Further study of two-term second-order differential equations with regularly varying nonlinearities, the right side of which preserves the sign in the neighborhood of singular point (both finite or equals $\pm \infty$ ) is carried out by Evtukhov V.M. on $P_{\omega}\left(\lambda_{0}\right)$-solutions, which arises in the study of generalized $n$-th order Emden - Fowler equations. Among the set of such solutions of equation under study we distinguish a fairly wide class of so-called $P_{\omega}\left(Y_{0}, Y_{1}, \lambda_{0}\right)$-solutions (generalization of $P_{\omega}\left(\lambda_{0}\right)$-solutions). The set of all $P_{\omega}\left(Y_{0}, Y_{1}, \lambda_{0}\right)$-solutions by its asymptotic properties separate into 4 disjoint classes of solutions corresponding to the values of $\lambda_{0}: \lambda_{0} \in \mathbb{R} \backslash\{0,1\}$ is nonsingular case, $\lambda_{0}=0, \lambda_{0}=1$, $\lambda_{0}= \pm \infty$ are particular cases. This type of solution was previously introduced in the study of the two-term equation $y^{\prime \prime}=\alpha_{0} p(t) \varphi_{0}(y) \varphi_{1}\left(y^{\prime}\right)$, where, $\alpha_{0} \in\{-1,1\}, p:[a, \omega[\longrightarrow] 0,+\infty[$ is continuous function, $\left.\varphi_{i}: \Delta_{Y_{i}} \longrightarrow\right] 0,+\infty\left[(i=0,1)\right.$ are regularly varying as $z \rightarrow Y_{i}(i=0,1)$ functions of $\sigma_{i}(i=0,1)$ orders, and $\sigma_{0}+\sigma_{1} \neq 1$. The case $\sigma_{0}+\sigma_{1}=1$ corresponds to the so-called semilinear differential equations, which have a number of properties of both linear and nonlinear differential equations. Thus, for an equation $y^{\prime \prime}=p(t)|y|^{1-\lambda}\left|y^{\prime}\right|^{\lambda} \operatorname{sgn} y$ with some constraints on a function $p$ (in particular, if the function preserves the sign, it is locally absolutely continuous and $\int_{a}^{\omega} p^{\frac{1}{2-\lambda}}(t) d t=+\infty, \lim _{t \rightarrow \omega} p^{\prime}(t) p^{\frac{\lambda-3}{2-\lambda}}(t)=l_{0}\left(\left|l_{0}\right| \leq+\infty\right)$, asymptotic representations are found as $t \rightarrow \omega$ for all types of proper solutions of this equation by Evtukhov V.M.. Here, for the equation we are studying, the necessary as well as sufficient conditions for the existence of $P_{\omega}\left(Y_{0}, Y_{1}, \lambda_{0}\right)$ - solutions are found, asymptotic representations of such solutions and their first-order derivatives are established, and the number of parametric families of such solutions is indicated.

Key words and phrases: two-term equation, $P_{\omega}\left(Y_{0}, Y_{1}, \lambda_{0}\right)$-solutions, regularly varying function, asymptotic representations of solutions, one-, two-parameter family of solutions.

Odesa National Marine University, Odesa, Ukrain

e-mail: lk09032017@gmail.com

УДК 517.925

2010 Mathematics Subject Classification: 34A34, 34E99.

Information on some grant ... 


\section{INTRODUCTION}

Consider the differential equation

$$
y^{\prime \prime}=\alpha_{0} p(t) \varphi_{0}(y)\left|y^{\prime}\right|^{\sigma_{1}}
$$

where $\alpha_{0} \in\{-1,1\}, p:[a, \omega[\longrightarrow] 0,+\infty[$ is a continuous function, $-\infty<a<\omega \leq+\infty$, $\left.\varphi_{0}: \Delta_{Y_{0}} \longrightarrow\right] 0,+\infty\left[\right.$ is continuous and regular varying as $y \rightarrow Y_{0}$ function of orders $\sigma_{0}$, $\Delta_{Y_{i}}(i \in\{0,1\})$ is a one-side neighborhood of $Y_{i}$ and $Y_{i} \in\{0 ; \pm \infty\}(i \in\{0,1\})$. We assume that the numbers $\mu_{i}(i=0,1)$ given by the formula

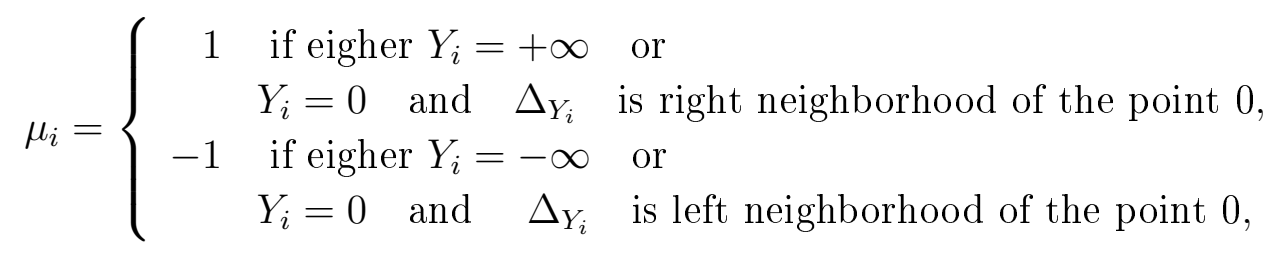

satisfy the relations

$$
\mu_{0} \mu_{1}>0 \text { for } Y_{0}= \pm \infty \text { and } \mu_{0} \mu_{1}<0 \text { for } Y_{0}=0
$$

Conditions (2) are necessary for the existence of solutions of equation (1) defined in a left neighborhood of $\omega$ and satisfying the conditions

$$
y^{(i)}(t) \in \Delta_{Y_{i}} \quad \text { for } t \in\left[t_{0}, \omega\left[, \quad \lim _{t \uparrow \omega} y^{(i)}(t)=Y_{i} \quad(i=0,1) .\right.\right.
$$

We study equation (1) on class $P_{\omega}\left(Y_{0}, Y_{1}, \lambda_{0}\right)$ - solutions, that defined as follows.

Definition 1. A solution y of equation (1) on interval $\left[t_{0}, \omega\left[\subset\left[a, \omega\left[\right.\right.\right.\right.$ is called $P_{\omega}\left(Y_{0}, Y_{1}, \lambda_{0}\right)$ solution, where $-\infty \leq \lambda_{0} \leq+\infty$, it, in addition to (3), it satisfies the condition

$$
\lim _{t \uparrow \omega} \frac{\left[y^{\prime}(t)\right]^{2}}{y(t) y^{\prime \prime}(t)}=\lambda_{0} .
$$

Depending on $\lambda_{0}$ these solutions have different asymptotic properties. For $\lambda_{0} \in \mathbb{R} \backslash\{1\}$ in [2] such ratios

$$
\lim _{t \uparrow \omega} \frac{\pi_{\omega}(t) y^{\prime}(t)}{y(t)}=\frac{\lambda_{0}}{\lambda_{0}-1}, \quad \lim _{t \uparrow \omega} \frac{\pi_{\omega}(t) y^{\prime \prime}(t)}{y^{\prime}(t)}=\frac{1}{\lambda_{0}-1}
$$

where

$$
\pi_{\omega}(t)=\left\{\begin{array}{ccc}
t & \text { if } \quad \omega=+\infty \\
t-\omega & \text { if } \quad \omega<+\infty
\end{array}\right.
$$

are established.Let us emphasize that for $\lambda_{0}=0$ the existence of $\lim _{t \uparrow \omega} \frac{y^{\prime \prime}(t) \pi_{\omega}(t)}{y^{\prime}(t)}$ (finite or equal to $\pm \infty)$ is assumed.

Note that the numbers $\mu_{0}, \mu_{1}$ determine the signs of any $P_{\omega}\left(Y_{0}, Y_{1}, \lambda_{0}\right)$ - solution of equation (1) and its derivative in a left neighborhood of $\omega$. In addition, the sign of the second 
derivative of any $P_{\omega}\left(Y_{0}, Y_{1}, \lambda_{0}\right)$-solution of equation (1) in a left neighborhood $\omega$ coincides with $\alpha_{0}$. Then taking into account (2), we have

$$
\alpha_{0} \mu_{1}>0 \quad \text { as } \quad Y_{1}= \pm \infty \quad \text { and } \quad \alpha_{0} \mu_{1}<0 \quad \text { as } \quad Y_{1}=0 \text {. }
$$

By the definition of a regularly varying function ( [1], Chap. 1, Sec. 1.1 9-10 of the Russian translation), each of the functions $\varphi_{0}$ admits a representation of the form

$$
\varphi_{0}(z)=|z|^{\sigma_{0}} L_{0}(z)
$$

where $\left.L_{0}: \Delta_{Y_{i}} \longrightarrow\right] 0,+\infty\left[\right.$ is a continuous function slowly varying as $y \rightarrow Y_{0}$ and satisfying the condition

$$
\lim _{y \rightarrow Y_{0}} \frac{L(\lambda y)}{L(y)}=1 \quad \text { for any } \quad \lambda>0,
$$

and the condition is satisfied uniformly for $\lambda$ on any interval $[c, d] \subset] 0,+\infty[$. Moreover, there exist continuously differentiable functions (see [1], Chap. 1, Sec. 1.1 10-15 of the Russian translation]) $\left.L_{00}: \Delta_{Y_{i}} \longrightarrow\right] 0,+\infty$ [ slowly varying as $y \rightarrow Y_{0}$ and satisfying the conditions

$$
\lim _{\substack{y \rightarrow Y_{0} \\ y \in \Delta Y_{0}}} \frac{L_{0}(y)}{L_{00}(y)}=1, \quad \lim _{\substack{y \rightarrow Y_{0} \\ y \in \Delta_{Y_{0}}}} \frac{y L_{00}^{\prime}(y)}{L_{00}(y)}=0 .
$$

Asymptotic representations and conditions of the existence of $P_{\omega}\left(Y_{0}, Y_{1}, \lambda_{0}\right)$ - solutions in case $\sigma_{0}+\sigma_{1} \neq 1$ are obtained in [6] for differential equation in general view. In each of the cases $\lambda_{0} \in \mathbf{R} \backslash\{0,1\}, \lambda_{0}=0, \lambda_{0}=1, \lambda_{0}= \pm \infty$ a condition $(R N)_{\lambda_{0}}$ is imposed on the right-hand side of the equation under which the equation becomes close in a sense to the two-term as $t \uparrow \omega$.

Here we study the behavior of $P_{\omega}\left(Y_{0}, Y_{1}, \lambda_{0}\right)$ - solutions in case $\sigma_{0}+\sigma_{1}=1$ and $\lambda_{0} \in \mathbb{R} \backslash\{1\}$, when it becomes close in some sense to the linear, which is studied in detail in the monograph [5]. The purpose of this article is to generalize the results from work [3] on equation (1).

We choose a number $b \in \Delta_{Y_{0}}$ such that the inequality

$$
|b|<1 \quad \text { for } \quad Y_{0}=0, \quad b>1(b<-1) \quad \text { for } \quad Y_{0}=+\infty\left(Y_{0}=-\infty\right)
$$

is respected and put

$$
\begin{aligned}
& \Delta_{Y_{0}}(b)=\left[b, Y_{0}\left[\quad \text { if } \quad \Delta_{Y_{0}} \quad \text { is a left neighborhood of } Y_{0},\right.\right. \\
& \left.\left.\Delta_{Y_{0}}(b)=\right] Y_{0}, b\right] \quad \text { if } \quad \Delta_{Y_{0}} \quad \text { is a right neighborhood of } Y_{0} .
\end{aligned}
$$

Now we introduce auxiliary functions and notation as follows:

$$
\begin{aligned}
& \Phi: \Delta_{Y_{0}}(b) \longrightarrow \mathbb{R}, \quad \Phi(y)=\int_{B}^{y} \frac{d s}{s L_{0}(s)}, \quad B=\left\{\begin{array}{l}
b \quad \text { if } \quad \int_{b}^{Y_{0}} \frac{d s}{s L_{0}(s)}= \pm \infty \\
Y_{0} \quad \text { if } \quad \int_{b}^{Y_{0}} \frac{d s}{s L_{0}(s)}=\text { const }
\end{array}\right. \\
& Z=\lim _{y \rightarrow Y_{0}} \Phi(y)=\left\{\begin{array}{cll}
0 & \text { if } B=Y_{0}, \\
+\infty & \text { if } B=b \quad \text { and } \mu_{0} \mu_{1}>0, \\
-\infty & \text { if } \quad B=b \text { and } \mu_{0} \mu_{1}<0,
\end{array} \quad \mu_{2}=\left\{\begin{array}{cll}
1 & \text { if } & B=b, \\
-1 & \text { if } & B=Y_{0},
\end{array}\right.\right.
\end{aligned}
$$




$$
I_{0}(t)=\int_{A_{0}}^{t} p(\tau)\left|\pi_{\omega}(\tau)\right|^{\sigma_{0}} d \tau, \quad I_{1}(t)=\int_{A_{1}}^{t} p(\tau)\left|\pi_{\omega}(\tau)\right|^{-\sigma_{1}} d \tau,
$$

where the integration limits $A_{i} \in\{a ; \omega\}(i=0,1)$ are chosen so as to ensure that the integrals $I_{i}(i=0,1)$ tend either to zero or to $\pm \infty$ as $t \uparrow \omega$.

Note that due to the choice $\mu_{0}, \mu_{1}, \mu_{2}$

$$
\operatorname{sign} \Phi(y)=\mu_{0} \mu_{1} \mu_{2} \quad \text { as } \quad y \in \Delta_{Y_{0}}(b) \backslash\{b\}
$$

Since the function $\Phi$ is strictly monotonic on the interval $\Delta_{Y_{0}}(b)$ and the range of its value is the interval

$$
\Delta_{Z}(c)=\left\{\begin{array}{lll}
{[c, Z[} & \text { if } \quad \mu_{0}>0 \\
] Z, c] & \text { if } \quad \mu_{0}<0
\end{array}\right.
$$

where $c=\Phi(b)$, then for it there is a continuously differentiable inverse function $\Phi^{-1}$ : $\Delta_{Z}(c) \rightarrow \Delta_{Y_{0}}(b)$, for which $\lim _{z \rightarrow Z} \Phi^{-1}=Y_{0}$.

It is easy to check that the function $\Phi(y)$ is slowly varying at $y \rightarrow Y_{0}$. Consequently, the inverse to it $\Phi^{-1}(z)$ at $z \rightarrow Z$ is a rapidly varying function. The question remains what the function $L\left(\Phi^{-1}(z)\right)$ will be like at $z \rightarrow Z$. In some cases (for example, for functions with a finite limit at $y \rightarrow Y_{0}$, or for functions of the form $|\ln | y||^{k_{1}}, \ln \ln ^{k_{2}}|\ln | y||, k_{1} \in \mathbb{R} \backslash\{1\}, k_{2} \in \mathbb{R}$, $\left.\exp \left(|\ln | y||^{k_{3}}\right), 0<k_{3}<1\right)$ it is regularly varying at $y \rightarrow Y_{0}$.

In addition, by virtue of the choice $\mu_{0}, \mu_{1}, \mu_{2}$ we have $\operatorname{sign} \Phi(y)=\mu_{0} \mu_{1} \mu_{2}$ at $y \in \Delta_{Y_{0}}(b) \backslash$ $\{b\}$.

\section{Section With Results}

Theorem. Let $\lambda_{0} \in \mathbb{R} \backslash\{1\}$ and let the function $L_{0}\left(\Phi^{-1}(z)\right)$ is regular varying of $\gamma$-th order as $z \rightarrow Z$, moreover, let the order $\sigma_{0}$ of the function $\varphi_{0}$ regularly varying as $y \rightarrow Y_{0}$ satisfy the condition $\sigma_{0}+\sigma_{1}=1$. Besides for $\lambda_{0}=0$ exists (finite or equal to $\pm \infty$ ) $\lim _{t \uparrow \omega} \frac{\left|\pi_{\omega}(t)\right|^{\sigma} p(t)}{I_{1}(t)}$. Then, for the existence of $P_{\omega}\left(Y_{0}, Y_{1}, \lambda_{0}\right)$ - solutions of the differential equation (1), it is necessary and, if the condition

$$
\left(\sigma_{0}+\lambda_{0}\right)\left(\left(\sigma_{0}+\lambda_{0}\right)(1+\gamma)-\gamma\right) \neq 0
$$

is satisfied, sufficient that, along with inequality (2), (5) the conditions

$$
\begin{gathered}
\lim _{t \uparrow \omega} \frac{\left|\pi_{\omega}(t)\right|^{\sigma_{0}} p(t)}{I_{1}(t)}=-\beta, \quad \lim _{t \uparrow \omega} \mu_{0} \mu_{1}\left|\lambda_{0}\right|^{\sigma_{1}}\left|\lambda_{0}-1\right|^{\sigma_{0}} I_{0}(t)=Z, \\
\lim _{t \uparrow \omega} I_{1}(t) \pi_{\omega}(t) L_{0}\left(\Phi^{-1}\left(\mu_{0} \mu_{1}\left|\lambda_{0}\right|^{\sigma_{1}}\left|\lambda_{0}-1\right|^{\sigma_{0}} I_{0}(t)\right)\right)=-\frac{\left|\lambda_{0}\right|^{\sigma_{0}}}{\left|\lambda_{0}-1\right|^{1+\sigma_{0}}},
\end{gathered}
$$

and the sign conditions

$$
\left.\mu_{2} I_{0}(t)>0, \quad \alpha_{0} \mu_{1}\left(\lambda_{0}-1\right) \pi_{\omega}(t)>0 \quad \text { for } \quad t \in\right] a, \omega[
$$


hold. Moreover, each solution of this kind admits the asymptotic representations

$$
\begin{gathered}
\Phi(y(t))=\mu_{0} \mu_{1}\left|\lambda_{0}\right|^{\sigma_{1}}\left|\lambda_{0}-1\right|^{\sigma_{0}} I_{0}(t)[1+o(1)], \\
\left.\frac{y^{\prime}(t)}{y(t)}=-\mu_{0} \mu_{1} \beta\left|\lambda_{0}\right|^{\sigma_{1}}\left|\lambda_{0}-1\right|^{\sigma_{0}} I_{1}(t) L_{0}\left(\Phi^{-1}\left(\mu_{0} \mu_{1}\left|\lambda_{0}\right|^{\sigma_{1}}\left|\lambda_{0}-1\right|^{\sigma_{0}} I_{0}(t)\right)\right)\right) \quad \text { as } \quad t \uparrow \omega,
\end{gathered}
$$

and if $\beta\left(\sigma_{0}+\lambda_{0}\right)\left(\lambda_{0}-1\right)<0$ such solutions form a one-parameter family if $\left(\sigma_{0}+\lambda_{0}\right)\left(\left(\sigma_{0}+\lambda_{0}\right)(1+\gamma)-\gamma\right) h_{2}(t)>0$ for $\left.t \in\right] a, \omega[$ and two-parameter family if $\left(\sigma_{0}+\lambda_{0}\right)\left(\left(\sigma_{0}+\lambda_{0}\right)(1+\gamma)-\gamma\right) h_{2}(t)<0$ for $\left.t \in\right] a, \omega[$.

Proof. Necessity. Let $\lambda_{0} \in \mathbf{R} \backslash\{0,1\}$ and и $y:\left[t_{0}, \omega\left[\rightarrow \Delta_{Y_{0}}\right.\right.$ be an arbitrary $P_{\omega}\left(Y_{0}, Y_{1}, \lambda_{0}\right)-$ solution of equation(1). Then there is a number $t_{1} \in\left[t_{0}, \omega\left[\right.\right.$ such that $y^{(k)}(t) \neq 0(k=0,1,2)$, $\operatorname{sign} y^{(k)}(t)=\mu_{k}(k=0,1)$ at $t \in\left[t_{1}, \omega\left[\right.\right.$. In addition, the definition of the $P_{\omega}\left(Y_{0}, Y_{1}, \lambda_{0}\right)-$ solution for $\lambda_{0} \in \mathbf{R} \backslash\{0,1\}$ (for $\lambda_{0}=0$ B in the case of existence $\lim _{t \uparrow \omega} \frac{y^{\prime \prime}(t) \pi_{\omega}(t)}{y^{\prime}(t)}$ ) immediately implies the fulfillment of limit equalities (4), using which, taking into account $\sigma_{0}+\sigma_{1}=1$, from equation (1) we have

$$
y^{\prime \prime}(t)=\alpha_{0} p(t)|y(t)|\left|\frac{\lambda_{0}}{\left(\lambda_{0}-1\right) \pi_{\omega}(t)}\right|^{\sigma_{1}} L_{0}(y(t))[1+o(1)] \quad \text { as } \quad t \uparrow \omega .
$$

From the last equality we have

$$
\frac{y^{\prime \prime}(t)}{y(t) L_{0}(y(t))}=\alpha_{0} \mu_{0}\left|\frac{\lambda_{0}}{\left(\lambda_{0}-1\right)}\right|^{\sigma_{1}} p(t)\left|\pi_{\omega}(t)\right|^{-\sigma_{1}}[1+o(1)] \quad \text { as } \quad t \uparrow \omega
$$

whence, taking into account the second of relations (4), we obtain the equality

$$
\frac{y^{\prime}(t)}{y(t) L_{0}(y(t))}=\mu_{0} \mu_{1}\left|\lambda_{0}\right|^{\sigma_{1}}\left|\lambda_{0}-1\right|^{\sigma_{0}} p(t)\left|\pi_{\omega}(t)\right|^{\sigma_{0}}[1+o(1)] \quad \text { as } \quad t \uparrow \omega .
$$

Integrating the last relation on a segment $\left[A_{0}, t\right]$, we obtain (14). In addition, by virtue of (8), (9) from (14) implies the first of the sign conditions (13) and the second of the limit equalities (11).

For $\lambda_{0} \in \mathbf{R} \backslash\{1\}$ it is also obvious in view of (4) that the second of the sign conditions (13) is satisfied.

Given the equality

$$
\left(\frac{y^{\prime}(t)}{y(t) L_{00}(y(t))}\right)^{\prime}=\frac{y^{\prime \prime}(t)}{y(t) L_{00}(y(t))}\left(1-\frac{\left(y^{\prime}(t)\right)^{2}}{y^{\prime \prime}(t) y(t)}-\frac{\left(y^{\prime}(t)\right)^{2}}{y^{\prime \prime}(t) y(t)} \frac{L_{00}^{\prime}(y(t)) y(t)}{L_{00}(y(t))}\right),
$$

by virtue of the definition of a slowly varying function and the definition of a , $P_{\omega}\left(Y_{0}, Y_{1}, \lambda_{0}\right)-$ solution we have

$$
\left(\frac{y^{\prime}(t)}{y(t) L_{00}(y(t))}\right)^{\prime}=\frac{y^{\prime \prime}(t)}{y(t) L_{00}(y(t))}\left(1-\lambda_{0}\right)(1+o(1)) \quad \text { as } \quad t \uparrow \omega
$$

from which in view of (16), (7) it follows

$$
\frac{y^{\prime}(t)}{y(t) L_{0}(y(t))}=-\mu_{0} \mu_{1} \beta\left|\lambda_{0}\right|^{\sigma_{1}}\left|\lambda_{0}-1\right|^{\sigma_{0}} I_{1}(t)[1+o(1)] \quad \text { as } \quad t \uparrow \omega .
$$


Comparing relations (17) и (18), we obtain the first of conditions (11). Also from (18) by virtue of (1) we have the condition

$$
\frac{y^{\prime \prime}(t) \pi_{\omega}(t)}{y^{\prime}(t)}=-\frac{\beta p(t)\left|\pi_{\omega}(t)\right|^{\sigma_{0}}}{\left(\lambda_{0}-1\right) I_{1}(t)}[1+o(1)] \quad \text { as } \quad t \uparrow \omega,
$$

which in the case $\lambda_{0}=0$, due to the existence of the limit $\frac{p(t)\left|\pi_{\omega}(t)\right| \sigma_{0}}{\left(\lambda_{0}-1\right) I_{1}(t)}$, guarantees the fulfillment of the asymptotic representations (4) for all $\lambda_{0} \in \mathbb{R} \backslash\{1\}$. Further, we note that condition (14) since the function $L_{0}(\Phi(z))$ as $z \rightarrow Z$ is of a regularly varying order $\gamma$, implies that

$$
L_{0}(y(t))=L_{0}\left(\Phi^{-1}\left(\mu_{0} \mu_{1}\left|\lambda_{0}\right|^{\sigma_{1}}\left|\lambda_{0}-1\right|^{\sigma_{0}} I_{0}(t)\right)\right)[1+o(1)] \quad \text { as } \quad t \uparrow \omega .
$$

Due to the last equality, taking into account (18) we obtain (15), and also, multiplying both sides of (18) by $\pi_{\omega}(t)$, taking into account(4), we get condition (12).

Sufficiency. Suppose, along with (2), (5), (11) - (13), condition (10) is satisfied. Let us show that in this case the differential equation (1) has $P_{\omega}\left(Y_{0}, Y_{1}, \lambda_{0}\right)$-solutions admitting representations (14), (15) and clarify the question of the number of such solutions.

Applying to the differential equation (1) the transformation

$$
\begin{aligned}
& \left.\frac{y^{\prime}(t)}{y(t)}=-\beta C I_{1}(t) L_{0}\left(\Phi^{-1}\left(C I_{0}(t)\right)\right)\right)\left[1+v_{1}(\tau)\right], \quad \Phi(y(t))=C I_{0}(t)\left[1+v_{2}(\tau)\right], \\
& \tau=\beta \ln \left|\pi_{\omega}(t)\right|, \quad C=\mu_{0} \mu_{1} \beta\left|\lambda_{0}\right|^{\sigma_{1}}\left|\lambda_{0}-1\right|^{\sigma_{0}},
\end{aligned}
$$

we obtain the system of differential equations

$$
\left\{\begin{aligned}
v_{1}^{\prime}= & \beta h_{1}(\tau)\left(\frac{-\alpha_{0} \mu_{0}}{C}\left|g_{1}(\tau)\right|^{\sigma_{1}} H\left(\tau, v_{2}\right)\left|1+v_{1}\right|^{\sigma_{1}}+\right. \\
& \left.+\frac{\beta g_{1}(\tau)}{h_{1}(\tau)}\left(1+v_{1}\right)^{2}-\left(1+v_{1}\right)\left(1+g_{1}(\tau) g_{2}(\tau)\right)\right) \\
v_{2}^{\prime}= & h_{2}(\tau)\left(-\frac{\left(1+v_{1}\right)}{H\left(\tau, v_{2}\right)}-h_{1}(\tau)\left(1+v_{2}\right)\right)
\end{aligned}\right.
$$

where

$$
\begin{aligned}
& h_{1}(\tau(t))=\frac{I_{1}^{\prime}(t) \pi_{\omega}(t)}{I_{1}(t)}, \quad H\left(\tau(t), v_{2}\right)=\frac{L_{0}\left(\Phi^{-1}\left(C I_{0}(t)\left(1+v_{2}\right)\right)\right.}{L_{00}\left(\Phi^{-1}\left(C I_{0}(t)\right)\right.}, \\
& g_{1}(\tau(t))=C \pi_{\omega}(t) I_{1}(t) L_{00}\left(\Phi^{-1}\left(C I_{0}(t)\right)\right), \\
& h_{2}(\tau(t))=\frac{I_{1}(t) \pi_{\omega}(t)}{I_{0}(t)}, \quad g_{2}(\tau(t))=\frac{\Phi^{-1}\left(C I_{0}(t)\right) L_{00}^{\prime}\left(\Phi^{-1}\left(C I_{0}(t)\right)\right.}{L_{00}\left(\Phi^{-1}\left(C I_{0}(t)\right)\right.}
\end{aligned}
$$

Since the function $\tau(t)=\beta \ln \left|\pi_{\omega}(t)\right|$ is such that

$$
\tau:\left[a_{0}, \omega\left[\longrightarrow \left[\tau_{0},+\infty\left[\quad ( \tau _ { 0 } = \beta \operatorname { l n } | \pi _ { \omega } ( a ) | ) , \quad \tau ^ { \prime } ( t ) > 0 \quad \text { as } \quad t \in \left[a_{0}, \omega\left[, \quad \lim _{t \uparrow \omega} \tau(t)=+\infty,\right.\right.\right.\right.\right.\right.
$$

then by virtue of the first of conditions (11)

$$
\begin{aligned}
& \lim _{\tau \rightarrow+\infty} h_{1}(\tau)=\lim _{t \rightarrow \omega} h(\tau(t))=-1, \quad \lim _{\tau \rightarrow+\infty} h_{2}(\tau)=\lim _{t \rightarrow \omega} h(\tau(t))=0, \\
& \quad \int_{\tau_{1}}^{+\infty}\left|h_{2}(\tau)\right| d \tau=+\infty, \quad \lim _{\tau \rightarrow+\infty} \frac{h_{2}^{\prime}(\tau)}{h_{2}(\tau)}=0
\end{aligned}
$$


where $\tau$ is any number from the interval $] \tau_{0},+\infty[$.

In view of the second of conditions (11), (13) and (8), (9) there exists a number $\left.t_{1} \in\right] a, \omega[$ such, that $\mu_{0} \mu_{1}\left|\lambda_{0}\right|^{\sigma_{1}}\left|\lambda_{0}-1\right|^{\sigma_{0}} I_{0}(t)\left(1+v_{2}\right) \in \Delta_{Z(\text { c) }}$ for $t \in\left[t_{1}, \omega\left[\right.\right.$ и $\left|v_{2}\right| \leq \frac{1}{2}$. Consider system (19) on the set $\left[\tau_{1},+\infty\left[\times \mathbb{R}_{\frac{1}{2}}^{2}\right.\right.$, where $\tau_{1}=\beta \ln \left|\pi_{\omega}\left(t_{1}\right)\right|, \mathbb{R}_{\frac{1}{2}}^{2}=\left\{\left(v_{1}, v_{2}\right) \in \mathbb{R}^{2}:\left|v_{i}\right| \leq 1 / 2, i=\right.$ $1,2\}$, on which the right-hand sides of the system are defined and continuous.

Since the function $L_{0}\left(\Phi^{-1}(z)\right)$ is regularly varying as $z \rightarrow Z$ of the order $\gamma$, it admits the representation $L_{0}\left(\Phi^{-1}(z)\right)=|z|^{\gamma} L(z)$, where $L$ is the slowly varying function as $z \rightarrow Z$. Therefore, according to (6)

$$
\begin{gathered}
L_{0}\left(\Phi^{-1}\left(C I_{0}(t)\left(1+v_{2}\right)\right)=\left|C I_{0}(t)\left(1+v_{2}\right)\right|^{\gamma} L\left(C I_{0}(t)\left(1+v_{2}\right)\right)=\right. \\
=\left|C I_{0}(t)\right|^{\gamma}\left|\left(1+v_{2}\right)\right|^{\gamma} L\left(C I_{0}(t)\right)\left[1+R\left(t, v_{2}\right)\right]=L_{0}\left(\Phi^{-1}\left(C I_{0}(t)\right)\left|\left(1+v_{2}\right)\right|^{\gamma}\left[1+R\left(t, v_{2}\right)\right],\right.
\end{gathered}
$$

where

$$
\lim _{t \uparrow \omega} R\left(t, v_{2}\right)=0 \quad \text { uniformly over } \quad\left|v_{2}\right| \leq \frac{1}{2} .
$$

Therefore, taking into account (7) we have

$$
H\left(\tau, v_{2}\right)=\left|\left(1+v_{2}\right)\right|^{\gamma}\left[1+r_{1}\left(t, v_{2}\right)\right], \quad \frac{1}{H\left(\tau, v_{2}\right)}=\left|\left(1+v_{2}\right)\right|^{\gamma}\left[1+r_{2}\left(t, v_{2}\right)\right],
$$

where functions $r_{i}\left(t, v_{2}\right)(i=1,2)$ are continuous on the set $\left[\tau_{1},+\infty\left[\times \mathbb{R}_{\frac{1}{2}}^{2}\right.\right.$ and such that

$$
\lim _{\tau \rightarrow+\infty} r_{i}\left(\tau, v_{2}\right)=0 \quad(i=1,2) \quad \text { uniformly over } \quad\left|v_{2}\right| \leq \frac{1}{2}
$$

Obviously, that $\lim _{t \uparrow \omega} \Phi^{-1}\left(C I_{0}(t)\right)=Y_{0}$, therefore, by virtue of $(7),(11),(12)$

$$
\lim _{\tau \rightarrow+\infty} g_{1}(\tau)=-\frac{\beta \lambda_{0}}{\lambda_{0}-1} \quad \lim _{\tau \rightarrow+\infty} g_{2}(\tau)=0
$$

Now we rewrite system (20) in the form

$$
\left\{\begin{array}{l}
v_{1}^{\prime}=\beta\left(f_{1}\left(\tau, v_{1}, v_{2}\right)+\frac{\sigma_{0}+\lambda_{0}}{\lambda_{0}-1} v_{1}-\frac{\gamma}{\lambda_{0}-1} v_{2}+V_{1}\left(v_{1}, v_{2}\right)\right) \\
v_{2}^{\prime}=h_{2}(\tau)\left(f_{2}\left(\tau, v_{1}, v_{2}\right)-v_{1}+(1+\gamma) v_{2}+V_{2}\left(v_{1}, v_{2}\right)\right)
\end{array}\right.
$$

where

$$
\begin{gathered}
\lim _{\tau \rightarrow+\infty} f_{i}\left(\tau, v_{1}, v_{2}\right)=0 \quad(i=1,2) \quad \text { uniformly over }\left(v_{1}, v_{2}\right) \mathbb{R}_{\frac{1}{2}}^{2}, \\
\lim _{\left|v_{1}\right|+\left|v_{2}\right| \rightarrow 0} \frac{\partial V_{i}\left(v_{1}, v_{2}\right)}{\partial v_{j}}=0 \quad(i, j=1,2),
\end{gathered}
$$

whence it follows that $\lim _{\left|v_{1}\right|+\left|v_{2}\right| \rightarrow 0} \frac{V_{i}\left(v_{1}, v_{2}\right)}{\left|v_{1}\right|+\left|v_{2}\right|}=0 \quad(i=1,2)$. In addition, conditions $(21)$ are satisfied. Thus, for system (20) the conditions of Theorem 2.6 from [4] are satisfied. Therefore, this system has at least one solution $\left(v_{1}, v_{2}\right):\left[\tau_{1},+\infty\left[\longrightarrow \mathbb{R}_{\frac{1}{2}}^{2}\left(\tau_{2} \geq \tau_{1}\right)\right.\right.$, tending to zero as $\tau \rightarrow+\infty$. Due to transformation (20) each such solution corresponds to a solution $y$ of 
differential equation (1), admitting asymptotic representations (14), (15). It is easy to check that the indicated solution is a $P_{\omega}\left(Y_{0}, Y_{1}, \lambda_{0}\right)$ - solution of equation (1).

Also, based on Theorem 2.6 in [4], it is easy to find the number of families of solutions to system (20). By virtue of (10), for $\lambda_{0} \in \mathbb{R} \backslash\{1\}$, the determinant

$$
\left|\begin{array}{cc}
\frac{\sigma_{0}+\lambda_{0}}{\lambda_{0}-1} & \frac{-\gamma}{\lambda_{0}-1} \\
-1 & \gamma+1
\end{array}\right|
$$

is nonzero. Therefore, for $\beta \frac{\sigma_{0}+\lambda_{0}}{\lambda_{0}-1}<0$ and $h_{2}(\tau) \frac{\sigma_{0}+\lambda_{0}}{\lambda_{0}-1}\left|\begin{array}{ll}\frac{\sigma_{0}+\lambda_{0}}{\lambda_{0}-1} & \frac{-\gamma}{\lambda_{0}-1} \\ -1 & \gamma+1\end{array}\right|<0$ system (20) has a two-parameter family of solutions tending to zero as $\tau \rightarrow+\infty$. System (20) has a oneparameter family of solutions vanishing at infinity either for $\beta \frac{\sigma_{0}+\lambda_{0}}{\lambda_{0}-1}<0$ and $h_{2}(\tau) \frac{\sigma_{0}+\lambda_{0}}{\lambda_{0}-1}\left|\begin{array}{cc}\frac{\sigma_{0}+\lambda_{0}}{\lambda_{0}-1} & \frac{-\gamma}{\lambda_{0}-1} \\ -1 & \gamma+1\end{array}\right|>0$ or $\beta \frac{\sigma_{0}+\lambda_{0}}{\lambda_{0}-1}>0$ and $h_{2}(\tau) \frac{\sigma_{0}+\lambda_{0}}{\lambda_{0}-1}\left|\begin{array}{cc}\frac{\sigma_{0}+\lambda_{0}}{\lambda_{0}-1} & \frac{-\gamma}{\lambda_{0}-1} \\ -1 & \gamma+1\end{array}\right|<0$.

The theorem is completely proved.

In what follows, equation (1) should be studied at $\sigma_{0}+\sigma_{1}=1$ for values $\lambda_{0}=1$, $\lambda_{0}= \pm \infty$. It is also possible to extend the results of this work to an equation of the form $y^{\prime \prime}=\alpha_{0} p(t) \varphi_{0}(y) \varphi_{1}\left(y^{\prime}\right), \alpha_{0} \in\{-1,1\}, p:[a, \omega[\longrightarrow] 0,+\infty[$ where, $p:[a, \omega[\longrightarrow] 0,+\infty[$ is a continuous function $\left.\varphi_{i}: \Delta_{Y_{i}} \longrightarrow\right] 0,+\infty[(i=0,1)$ and are a continuous regularly varying as $z \rightarrow Y_{i}(i=0,1)$ functions of $\sigma_{i}(i=0,1)$ orders.

\section{REFERENCES}

[1] E. Seneta, Regularly varing functions. Lecture Notes in Mathematics, Vol. 508. Springer-Verlag, BerlinNew York, 1976.

[2] Evtukhov V. M. The asymptotic behavior of the solutions of one nonlinear second-order differential equation of the Emden - Fowler type.dis.... cand. fiz.-mat. nauk: 01.01.02 . Odesa, 1998, 154 p. (in Russian)

[3] Evtukhov V. M. Asymptotics of solutions of second-order non-autonomous ordinary differential equations asymptotically close to linear. UMG, 2012, Vol. 64, No. 10, P. 1346-1364. (in Russian)

[4] Evtukhov V. M., Samoylenko A.M. Asymptotics of solutions of second-order non-autonomous ordinary differential equations asymptotically close to linear. UMG, 2012, Vol. 64, No. 10, P. 1346-1364. (in Russian)

[5] Kiguradze, I.T. and Chanturiya, T.A. Asimptotic Properties of Solutions of Nonautonomous Ordinary Differential Equations, Moscow, 1990, 430 p. (in Russian)

[6] Kusick L.I. Asymptotic representations of solutions of second-order nonlinear differential equations.dis.... cand. fiz.-mat. nauk: 01.01.02. Odesa, 2016, 145 p. (in Russian) 
Кусік Л.І. Умови існування та асимптотика розв'язків одного класу диференціальних рівнянь другого порядку // Буковинський матем. журнал - 2020. - Т.8, №1. - С. 20-28.

Для диференціального рівняння другого порядку виду $y^{\prime \prime}=\alpha_{0} p(t) \varphi_{0}(y)\left|y^{\prime}\right|^{\sigma_{1}}$, де $\alpha_{0} \in$ $\{-1,1\}, p:\left[a, \omega[\longrightarrow] 0,+\infty\left[\right.\right.$-неперервна функція, $\left.\varphi_{0}: \Delta_{Y_{i}} \longrightarrow\right] 0,+\infty[$-неперервна правильно змінна при $y \rightarrow Y_{0}$ функція порядку $\sigma_{0}$, причому $\sigma_{0}+\sigma_{1}=1, \Delta_{Y_{i}}$ односторонній окіл $Y_{i}, Y_{i} \in\{0, \pm \infty\}(i \in\{0,1\})$ розглянуто питання існування розв'язків, для яких $\lim _{t \uparrow \omega} y^{(i)}(t)=Y_{i}(i \in\{0,1\})$.

Залучення у 80-х pp. XX ст. в працях V.Marič, M. Tomič при вивченні двочленних диференціальних рівнянь другого порядку з правильно змінними в нулі нелінійностями $y^{\prime \prime}=p(t) \varphi(y)$ дало змогу вказати двубічні оцінки розв'язків, що прямують до нуля при $t \rightarrow+\infty$. Подальше вивчання двочленних диференціальних рівнянь другого порядку 3 правильно змінними нелінійностями, права частина яких зберігає в околі особливій точки (як скінченній, так и рівній $\pm \infty$ ) знак, проведено на виділеному В.М.Євтуховим класі $P_{\omega}\left(\lambda_{0}\right)$ - розв'язків, що виникає при дослідженні узагальнених рівняннях Емдена - Фаулера $n$-го порядку. Серед множини розв'язків вивчаемого рівняяня відокремлюємо достатньо широкий клас т. з. $P_{\omega}\left(Y_{0}, Y_{1}, \lambda_{0}\right)$ - розв'язків (узагальнення $P_{\omega}\left(\lambda_{0}\right)-$ розв'язків). Множина усіх $P_{\omega}\left(Y_{0}, Y_{1}, \lambda_{0}\right)$ - розв'язків за своїми асимптотичними властивостями розпадається на 4 непертинаючихся класів розв'язків, що відповідають наступним значенням $\lambda_{0}: \lambda_{0} \in \mathbb{R} \backslash\{0,1\}$ - неособливий випадок, $\lambda_{0}=0, \lambda_{0}=1, \lambda_{0}= \pm \infty$ - особливі випадки. Такого типу розв'язки раніше було уведено при вивченні двочленного рівняння $y^{\prime \prime}=\alpha_{0} p(t) \varphi_{0}(y) \varphi_{1}\left(y^{\prime}\right)$, де $\alpha_{0} \in\{-1,1\}, p:[a, \omega[\longrightarrow] 0,+\infty[-$-неперервна функція, $\left.\varphi_{i}: \Delta_{Y_{i}} \longrightarrow\right] 0,+\infty\left[(i=0,1)\right.$-неперервні правильно змінні при $z \rightarrow Y_{i}(i=0,1)$ функції порядків $\sigma_{i}(i=0,1)$, причому $\sigma_{0}+\sigma_{1} \neq 1$. Випадок $\sigma_{0}+\sigma_{1}=1$ відповідає т.з. полулінійним диференціальним рівнянням, яким притаманні властивості як лінійних, так и нелінійних диференціальних рівнянь. Так, для рівняння $y^{\prime \prime}=p(t)|y|^{1-\lambda}\left|y^{\prime}\right|^{\lambda} \operatorname{sgn} y$ при деяких обмеженнях на функцію $p$ (зокрема, якщо функція $p:[a, \omega[\longrightarrow] 0,+\infty[$ зберігає знак, локально абсолютно неперервна i $\int_{a}^{\omega} p^{\frac{1}{2-\lambda}}(t) d t=+\infty, \lim _{t \rightarrow \omega} p^{\prime}(t) p^{\frac{\lambda-3}{2-\lambda}}(t)=l_{0}\left(\left|l_{0}\right| \leq+\infty\right)$, В.М.Євтуховим знайдено асимптотичні зображення при $t \rightarrow \omega$ усіх типів правильних розв'язків цього рівняння. Тут для рівняння, що вивчаємо, знайдено необхідні, а також достатні умови існування $P_{\omega}\left(Y_{0}, Y_{1}, \lambda_{0}\right)$ - розв'язків, встановлено асимптотичні зображення таких розв'язків та їх похідних першого порядку, вказано кількість параметричних сімей таких розв'язків. 